\title{
Ethics of Health Research in Communities: Perspectives From the Southwestern United States
}

\author{
Robert L. Williams, MD, MPH \\ Catbleen E. Willging, $P b D^{3}$ \\ Gilbert Quintero, $P b D^{4}$ \\ Summers Kalishman, $P b D^{2}$ \\ Andrew L. Sussman, PbD ${ }^{1}$ \\ William L. Freeman, $M D^{5}$ \\ On bebalf of RIOS Net Members \\ 'Department of Family and Community \\ Medicine, University of New Mexico, Albu- \\ querque, New Mexico \\ ${ }^{2}$ Undergraduate Medical Education Pro- \\ gram Evaluation, University of New Mex- \\ ico, Albuquerque, New Mexico \\ ${ }^{3}$ Behavioral Health Research Center of the \\ Southwest, Albuquerque, New Mexico \\ ${ }^{4}$ Department of Anthropology, University \\ of Montana, Missoula, Montana \\ ${ }^{5}$ Northwest Indian College, Bellingham, \\ Washington

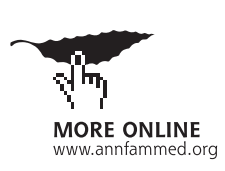

Conflicts of interest: none reported

\section{CORRESPONDING AUTHOR}

Robert L. Williams, MD, MPH

Department of Family and Community

Medicine

MSC09 5040

1 University of New Mexico

Albuquerque, NM 87131

rlwilliams@salud.unm.edu

\begin{abstract}
PURPOSE The increasing attention paid to community-based research highlights the question of whether human research protections focused on the individual are adequate to safeguard communities. We conducted a study to explore how community members perceive low-risk health research, the adequacy of human research protection processes, and the ethical conduct of community-based research.
\end{abstract}

METHODS Eighteen focus groups were conducted among rural and urban Hispanic and Native American communities in New Mexico using a semistructured guide. Group transcriptions were analyzed using iterative readings and coding, with review of the analytic summary by group members.

RESULTS Although participants recognized the value of health research, many also identified several adverse effects of research in their communities, including social (community and individual labeling, stigmatization, and discrimination) and economic (community job losses, increased insurance rates, and loss of community income). A lack of community beneficence was emphasized by participants who spoke of researchers who fail to communicate results adequately or assist with follow-through. Many group members did not believe current human research and data privacy processes were adequate to protect or assist communities.

CONCLUSIONS Ethical review of community-based health research should apply the Belmont principles to communities. Researchers should adopt additional approaches to community-based research by engaging communities as active partners throughout the research process, focusing on community priorities, and taking extra precautions to assure individual and community privacy. Plans for meaningful dissemination of results to communities should be part of the research design.

Ann Fam Med 2010;8:433-439. doi:10.1370/afm.1138.

\section{INTRODUCTION}

onverging organizational, conceptual, and funding developments during the last decade have raised the profile of health and medical research conducted in communities. At the same time, the number of practice-based research networks, organizations that specifically undertake research in primary care and community settings, has grown rapidly. ${ }^{1-5}$ With these developments, there has been increasing interest in the concept of community-based participatory research, whereby community members have more involvement in all stages of the research process. ${ }^{6,7}$ More recently, the National Institutes of Health's Clinical and Translational Science Awards program has included explicit expectations for community engagement in research and for development of research that can directly benefit communities. ${ }^{8}$ 
This growing interest in conducting research that directly or indirectly involves communities raises a concern about the adequacy of research protections. Human research protections established and expanded during the last 60 years have centered on the rights and safety of the individual in the research process. Indeed, the 3 principles of The Belmont Report (respect for persons, beneficence, and justice), which provide the ethical foundation for all current human research, were articulated in response to events that occurred to individuals in the name of research. ${ }^{9}$ Several authors have suggested, however, that these principles may offer inadequate protection when research is based in communities, particularly when those communities have readily identifiable features, when they have distinct cultural aspects that might be adversely affected by research, or when they have a history of having been subject to discrimination. ${ }^{10-12}$ Reflecting these concerns, some authors have argued for expansion of the Belmont principles (such as introducing a fourth principle: respect for communities). ${ }^{13,14}$ This argument is made on the basis of ethical reasoning and a few reports of adverse effects of health research in communities. To our knowledge there has not been a systematic effort to explore the perspectives of community residents on the experience and process of community-based health research as a basis for ethical review of research in communities. ${ }^{10}$ The absence of such empirical data is a clear shortcoming in discussions about ethics of research in communities and about the need to modify the Belmont principles.

We conducted this study among ethnic minority communities located in the Southwestern United States to assess views about community-based health research. Our overall goal was to gather empirical data about appropriate methods for conducting research in communities and to inform ethical discussions concerning this research. We focused on Hispanic/Latino and Native American communities for several reasons. First, these communities have had frequent experience with health and social science research. Second, there have been examples of difficult experiences with research and researchers among these communities. ${ }^{15-19}$ Third, a primary care, practice-based research network involving these communities now exists. We were particularly interested in what community members thought about the type of low-risk and health services research that such networks typically undertake. Our specific research objectives were to gather data about (1) how members of these communities view low-risk health services research, considering both its potential benefits and harms; (2) how they view processes for ensuring health information privacy and for human research protection; and (3) how researchers should ethically conduct research in communities.

\section{METHODS}

The study was conducted in communities across the state of New Mexico in association with a primary care practice-based research network, the Research Involving Outpatient Settings Network, or RIOS Net. Three-quarters of the patients seen by the 275 clinician members of RIOS Net are Hispanic/Latino or Native American.

We followed a qualitative design using focus groups to explore concerns about health data privacy and confidentiality among community residents. The focus groups allowed us to stimulate interactions that would not occur during individual interviews. The research team was composed of a family physician, 3 medical anthropologists, and an educator/program evaluator. Project consultants included a general internist/ethicist, a family physician/ethicist, and a qualitative research methodologist.

\section{Study Participants}

We used a purposive sampling design. Because we anticipated that ethnocultural groupings and community size would be key factors influencing views about research and privacy, we drew our focus groups from the 2 different ethnic minority groups and, within each group, from communities of different size. As our purpose was to understand broadly shared views within communities, our sampling process did not target unique subgroups.

\section{Sampling Level 1: Communities} Important variations exist within the Hispanic/Latino and Native American ethnocultural groups. In New Mexico, many persons of Hispanic ethnicity trace their roots back many generations and view themselves as culturally distinct from the more recently arrived immigrants. The Native Americans in New Mexico are predominantly Navajo or Pueblo. These 2 Native American groups, while sharing some common experiences, have distinct cultural differences.

New Mexico is largely rural, with more than onehalf the state's population living in communities of less than 25,000 population. ${ }^{20}$ To examine the influence of community size on attitudes toward health research and privacy, larger communities (populations of at least $25,000)$ and rural communities were used for sampling.

We organized 16 focus groups in the Hispanic and Native American communities across the state (Table 1). Two additional groups were composed of health care clinicians and staff from across RIOS Net, selected to complement the perspectives of the community residents.

\section{Sampling Level 2: Individual Group Members}

Focus group members were identified through local contacts in each community. Whenever feasible, we 


\begin{tabular}{|lc|}
\hline Table 1. Composition of Focus Groups \\
\hline Community & No. of Groups \\
\hline Native Hispanic (urban) & 2 \\
Native Hispanic (rural) & 2 \\
Immigrant Hispanic (urban) & 2 \\
Immigrant Hispanic (rural) & 2 \\
Navajo (urban) & 2 \\
Navajo (rural) & 2 \\
Pueblo (urban) & 2 \\
Pueblo (rural) & 2 \\
Health care clinicians/staff & 2 \\
\hline
\end{tabular}

selected participants who would represent a community cross-section by age and sex. Participants were recruited to join a group discussion about health research in their communities and were compensated $\$ 50$.

\section{Focus Group Guide}

We used a uniform guide to stimulate discussion about the participants' experiences with health research, cultural- or community-based factors that influence views on these topics, and the adequacy of research review guidelines for privacy protection. The guide was modified after feedback from a pilot focus group (Supple-

mental Appendix, available at http://annfammed. org/cgi/content/full/8/5/433/DC1).

\section{Data Collection}

Two investigators moderated each focus group and recorded observations. After informed consent was obtained from the group members, the focus groups were audio recorded. Where appropriate, group interactions were simultaneously translated into Spanish or Navajo (all Pueblo participants spoke English fluently).

\section{Data Processing and Analysis}

Transcripts of the focus group discussions were analyzed through a series of iterative readings, after which the data were systematically categorized into codes line by line, using NVivo qualitative analytic software. ${ }^{21}$ Two medical anthropologist investigators (G.Q., C.W.) independently coded transcriptions of 14 focus groups, identifying themes and relationships, without an a priori thematic list or structure. Neither data collection nor analysis was grounded in the concept of a fourth Belmont principle. Our initial research goal was to gather empirical data on appropriate methods of research in communities. Emergent themes in the data led to consideration of the fourth Belmont concept.

After an initial set of transcripts was coded, the research team met to resolve minor differences in coding themes and to consider revisions to the focus group guide. When the coding was completed, the analysts prepared an initial interpretive document that was then reviewed with the rest of the study team. Project consultants and representatives of the ethnic groups/communities next met with the study team to comment on the interpretive document. Only minor modifications resulted from each stage of this iterative review process, most likely because of the consistency and clarity of the themes emerging from the data. Finally, the interpretive document was distributed to coordinators of each focus group for review by all participants. All group members indicated they were in agreement with the summary.

The transcripts of the final 4 groups, those composed of Navajo participants, were reviewed independently by a third medical anthropologist analyst (A.S.) and then compared with and integrated into the main analytic structure.

\section{RESULTS}

\section{Sample}

The 18 focus groups included 155 participants (45 male): 35 native Hispanic participants, 32 immigrant Hispanic participants, 37 Pueblo participants, 36 Navajo participants, and 15 health care staff. The reported findings summarize emergent themes common to all groups, including those of health care staff.

\section{Impact of Health Research on Communities}

Overall, research was recognized as beneficial, particularly when it can enhance health and healing practices or education on the community level, or when it could benefit society more generally. As one participant stated, "In terms of medical research, I'm really for things that are going to benefit humankind."

At the same time, negative aspects of research conducted in communities were clearly identified. Many concerns emphasized the actions of researchers in communities, including coercion and inadequate attention to language and cultural issues. Two common themes expressed by participants were the frustration that community services often do not continue after funding for research projects ends, and the lack of communication to communities about the results of research: "How is this information passed on? Where does that information go? How is it disseminated?"

Participants expressed fears that health research could result in higher insurance rates for their communities or that services might even be denied if information from the research were made known. Similarly, some participants believed that there could be economic fallout, such as job loss, if research information were to become known outside the study and community. 
If people know that we have a high incidence of diabetes, that could skyrocket health insurance costs or workforce issues and now they're going to be out of work more because of this.

This unease about adverse economic effects of health research on communities directly relates to concerns expressed by many groups about increased discrimination resulting from labeling and stigmatization of small, rural, or ethnically identifiable communities when research results are released. In addition to the economic concerns, group members did not want community labeling to lead to targeted marketing.

They don't want to see the name of their tribe on the front page of the paper again saying they have more of something bad which leads to more discrimination against them.

Furthermore, discussion in several groups highlighted the difficulties of maintaining privacy in small or rural communities, the potential for labeling or stigmatization of individuals within communities, and the impact on relations within the community: "It goes back to that small-town mentality that we all have. If you're in a big huge place, you wouldn't know these things about a coworker."

\section{Ethical Conduct of Research in Communities}

The focus group guide did not directly solicit comment on how researchers should ethically conduct community-based research. Rather, by distilling comments related to research, we were able to infer participants' opinions concerning ethical community-based research practices. Those participants who expressed views about research review committees generally did not feel that they offered adequate protection and in a few cases mistrusted them. With regard to specific protection processes, some participants believed that informed consent processes did not guarantee either confidentiality or complete understanding. Language barriers impeded understanding of these documents.

Although the Belmont principles clearly specify that there must be beneficence for the individual research participant, group participants emphasized the lack of beneficence for their communities from research. They observed that research did not seem to improve their communities, that health services never seemed to get any better, that information did not come back to the communities or was too technical to be of practical value, and that research was not typically community driven.

Some of the concerns I have are you don't ever hear back, or that they do a research study, and they say, "Okay. This is the results. See you later." You know there's not a next step. There's no "Let's help design some interventions to deal with what the results of this health survey were."
Comments by participants emphasized not only the importance of individual privacy, particularly in the more difficult circumstances of small or rural communities, but also the importance of respect for privacy of the community itself.

\section{Other Community Research Issues}

We explored whether there exist culturally relevant benefits or harms of research that are unique to the Hispanic/Latino and Native American communities or differences in perspectives between the different ethnocultural groups. In general, we found that Native American group members more commonly referred to difficulties in past experiences with researchers and were more likely to emphasize the importance of building trust between researchers and communities.

Differences related to urban or rural residence of participants were much more apparent. One theme that emerged in discussions among participants from small or rural communities was the involvement of local residents in research data collection processes. Although some participants viewed involvement as a potential economic benefit to the community, others viewed it with less enthusiasm because they were concerned about a greater potential for loss of confidentiality.

\section{DISCUSSION}

Members of these Southwestern Hispanic and Native American communities articulated a number of issues that not only support a fourth Belmont principle (requiring respect for communities) but also call for more broadly applying the 3 principles of The Belmont Report to communities as well as individuals. This study is the first to provide empirical data in support of this perspective. The groups generally were in favor of health research, recognizing its potential benefits to individuals and communities alike. Some focus group participants trusted the research and confidentiality processes, as well as the researchers, but many other participants held opposing views. These participants viewed health research and researchers with suspicion, based not only on well-publicized examples of unethical practices in other settings, but also on repeated experiences with research that did not result in apparent community benefits.

Various harms were associated with communitybased research. These harms were primarily economic (eg, community job loss, increased insurance rates, loss of tourism dollars) and social (eg, discrimination against community members, negative labeling, and stigmatization of the community). Although these harms are not unique to the ethnic groups involved in this study, some were perhaps amplified by the ethnic 
and rural background of many participants. Participants particularly emphasized no or ineffective return of information about research results to the communities and apparent limited impact of research on their health or health care.

\section{Comparison With Published Literature}

Our findings are consistent with published concerns regarding the ethics of research involving communities. ${ }^{10,11,13,22-24}$ These articles, based largely on ethical reasoning, have suggested many of the potential harms described above. We are unaware of any previous studies that have validated these concerns through systematic collection of community members' perspectives.

Interestingly, although perhaps not surprisingly, the literature contains only a few descriptions of adverse effects of community-based health research. A few articles have published examples of adverse publicity to a community, of cultural insensitivity, and even of betrayal by health researchers, in some cases reportedly leading to ostracizing community members. ${ }^{23,25,26}$ Freeman and colleagues refer to the impact on cultural and religious beliefs resulting from the alleged misuse of biologic specimens obtained from the Havasupai as a recent example of community harms. ${ }^{15,16,27}$

This relative lack of published documentation of community harms resulting from health research does not mean that these harms have not frequently occurred. Indeed, the shared sense of their occurrence was so widespread among the communities we visited that the small number of published examples appears more likely to reflect the absence of a mechanism for systematically reporting them. Such a system, comparable to that used to report adverse events occurring in research involving individuals, might result in increased documentation of the frequency and severity of community-based harms.

\section{Guidelines and Recommendations}

For more than 25 years there has been a call to pay attention to the community in ethical review of proposed health research. ${ }^{13}$ In the last decade, Weijer and others have honed this concept by calling for the establishment of a fourth Belmont principle to assure respect for community. ${ }^{12,13,19,28}$ At the same time, a number of national and international organizations have moved to develop guidelines aimed at protecting communities from harms and increasing the benefits to communities from research. ${ }^{10,12,29-34}$ Several authors have proposed elements of the research process and its review to insure consideration of respect for communities. ${ }^{11,22,28,30,35-40}$ Major themes in our focus groups support such efforts.

\section{Current Practice and Challenges}

Research review committees in Native American communities have increasingly incorporated how the research would affect the community, and a model code for tribal research ${ }^{41,42}$ includes specific consideration of the effects of research on the community. Nevertheless, a recent publication analyzing the content of institutional review board processes at 30 leading health research institutions showed that many key elements widely proposed as important to consideration of the effects of research on a community are missing, and another recent publication has described the challenges associated with community-based research review. ${ }^{22,43}$

These challenges that accompany efforts to assure ethical conduct of community-based research have been well-described. Such questions as how to balance individual benefit-risk against community benefit-risk, how to resolve conflicting messages from different parts of a community, how to best identify community representatives in a diffuse and unstructured community, and how to resolve a community's request or requirement to suppress undesirable research findings, all require careful thought.

\section{Proposed Implications}

In reviewing our data, it would be a mistake to conclude that community-based research is best avoided. That most of our study participants found problems with previous approaches to community-based health research can be seen as a call for a new model of research. Traditionally, health research has been conducted by scientists working in relative isolation, with human "subjects" as passive partners. Data from this study suggest that, at least in these Southwestern Hispanic and Native American communities, this passive partnership has become less acceptable. The following are some implications of our findings:

1. Health researchers who want to conduct research in communities should first create an active partnership with community members. This partnership should include discussion of the need for the research, processes for protection from harms, plans for dissemination of results in ways that are meaningful to the communities, and plans for the community to benefit from the research. A flexible research design may be important to establishing a partnership that will lead to an acceptable plan.

2. Health researchers should be prepared to target their research to topics that are a priority for these communities, or be prepared to justify the focus of their research so that it is acceptable to the communities. 
3. High priority should be placed on research processes that ensure privacy of data and fully informed consent for research in communities, especially in small communities.

4. Health Insurance Portability and Accountability Act (HIPAA) compliance and institutional review board approval should be perceived as minimal, yet insufficient, requirements for conducting community-based research.

5. A mechanism must be created to provide infrastructure support for researchers to establish and maintain community relationships.

An example of how these principles can be feasibly and productively applied in practice-based research network research has been published. ${ }^{44}$

\section{Limitations}

Our study was restricted to groups of Southwestern Hispanic and Native American persons. Further research in other settings would help confirm the generalizability of our findings. We believe, however, that the relative uniformity of major themes across groups and the consistency of our findings with published theoretical concerns and with tribal and national guidelines suggest our findings are valid and generalizable.

Taken together, the data from this study suggest that the combination of negative experiences with research and researchers and a high level of sensitivity to confidentiality and loss of privacy, perhaps amplified by rural and ethnic factors, produce a challenging environment for health research in Southwestern Hispanic and Native American communities. Processes for research review and privacy protection, embodied by institutional review board and HIPAA regulations, represent an important foundation for conducting research in these communities, but they should not be seen as sufficient. Transparency, commitments to provide some form of return to the communities, and partnerships throughout the health research endeavor are needed to overcome this distrust and create productive health research with communities. Our data support a call for applying the 3 principles of The Belmont Report to communities as well as to individuals.

To read or post commentaries in response to this article, see it online at http://www.annfammed.org/cgi/content/full/8/5/433.

Key words: Principle-based ethics; confidentiality; third-party consent; community-based participatory research; privacy

Submitted March 27, 2009; submitted, revised, March 15, 2010; accepted March 17, 2010

Funding support: This project was supported by grant No. 1 R03 HS013208 from the Agency for Healthcare Research and Quality.
Presented at the Navajo Research Conference, June 2005, Fort Defiance, Arizona; and at the American Association of Medical Colleges annual meeting, November 2006, Seattle, Washington.

Acknowledgments: We acknowledge and appreciate the insights and advice that each of the focus group participants provided us. We appreciate the advice and important contributions to this study provided by Lynn Meadows, PhD, and Bernard Lo, MD.

\section{References}

1. Graham DG, Spano MS, Stewart TV, Staton EW, Meers A, Pace WD. Strategies for planning and launching PBRN research studies: a project of the Academy of Family Physicians National Research Network (AAFP NRN). J Am Board Fam Med. 2007;20(2):220-228.

2. Mold JW, Peterson KA. Primary care practice-based research networks: working at the interface between research and quality improvement. Ann Fam Med. 2005;3(Suppl 1):S12-S20.

3. Gilbert GH, Williams OD, Rindal DB, Pihlstrom DJ, Benjamin PL, Wallace MC; DPBRN Collaborative Group. The creation and development of the dental practice-based research network. J Am Dent Assoc. 2008;139(1):74-81.

4. Westfall JM, Mold J, Fagnan L. Practice-based research -"Blue Highways" on the NIH roadmap. JAMA. 2007;297(4):403-406.

5. Binns HJ, Lanier D, Pace WD, et al; Primary Care Network Survey (PRINS) Participants. Describing primary care encounters: the Primary Care Network Survey and the National Ambulatory Medical Care Survey. Ann Fam Med. 2007;5(1):39-47.

6. Minkler M, Wallerstein N, eds. Community Based Participatory Research for Health. San Francisco, CA: John Wiley and Sons; 2003.

7. National Institutes of Health. NCMHD Community-Based Participatory Research (CBPR) Initiative in Reducing and Eliminating Health Disparities. Intervention Research Phase (R24). May 2007. http:// grants.nih.gov/grants/guide/rfa-files/RFA-MD-07-003.html. Accessed Sep 29, 2008.

8. National Institutes of Health. Fact Sheet NCRR. Clinical and Translational Science Awards. May 2008. http://www.ncrr.nih.gov/publications/clinicaldiscipline/CTSA_FactSheet.pdf, Accessed Sep 29, 2008.

9. The National Commission for the Protection of Human Subjects of Biomedical and Behavioral Research, Office of the Secretary, Department of Health, Education, and Welfare. Regulations and Ethical Guidelines. The Belmont Report: Ethical Principles and Guidelines for the Protection of Human Subjects of Research. April 1979.http://www.hhs.gov/ohrp/humansubjects/guidance/belmont. htm. Accessed Jan 28, 2010.

10. Sharp RR, Foster MW. Community involvement in the ethical review of genetic research: lessons from American Indian and Alaska Native populations. Environ Health Perspect. 2002;110(Suppl 2):145-148.

11. Gbadegesin S, Wendler D. Protecting communities in health research from exploitation. Bioethics. 2006;20(5):248-253.

12. Weijer C, Anderson JA. A critical appraisal of protections for aboriginal communities in biomedical research. Jurimetrics. 2002 42(2):187-198.

13. Weijer C. Protecting communities in research: philosophical and pragmatic challenges. Camb Q Healthc Ethics. 1999;8(4):501-513.

14. Weijer C, Goldsand G, Emanuel EJ. Protecting communities in research: current guidelines and limits of extrapolation. Nat Genet. 1999;23(3):275-280.

15. Rubin P. Indian givers. Phoenix New Times. May 27, 2004. http:// www. phoenixnewtimes.com/2004-05-27/news/indian-givers. Accessed Feb 1, 2010.

16. Dalton R. When two tribes go to war. Nature. 2004;430(6999): 500-502. 
17. Goldzieher JW, Moses LE, Averkin E, Scheel C, Taber BZ. A placebocontrolled double-blind crossover investigation of the side effects attributed to oral contraceptives. Fertil Steril. 1971;22(9):609-623.

18. Goldzieher JW, Moses LE, Averkin E, Scheel C, Taber BZ. Nervousness and depression attributed to oral contraceptives: a double-blind, placebo-controlled study. Am J Obstet Gynecol. 1971;111(8):1013-1020.

19. Levine RJ. Ethics and Regulation of Clinical Research. 2nd ed. Baltimore, MD: Urban and Schwarzenberg; 1986. Chapter 4:71-72.

20. New Mexico by Place. GCT-PH1. Population, Housing Units, Area, and Density: 2000. http://factfinder.census.gov/servlet/GCTTable?_bm =yE-context=gct $\varepsilon$-ds_name =DEC_2000_SF1_uEmt_name $=$ DEC_2000_SF1_U_GCTPH1_ST1E-tree_id $=4001 \varepsilon$ redoLog $=$ false - -_caller $=$ geoselect $\delta$-geo_id $=04000$ uS35Eformat=ST-7|ST-7SE-_lang=en. Accessed Mar 26, 2009.

21. NVivo. http://www.qsrinternational.com. QSR International, Sept 2008. Accessed Sept29, 2008.

22. Flicker S, Travers R, Guta A, McDonald S, Meagher A. Ethical dilem mas in community-based participatory research: recommendations for institutional review boards. J Urban Health. 2007;84(4):478-493.

23. Darou WG, Hum A, Kurtness J. An investigation of the impact of psychosocial research on a Native population. Prof Psychol Res Pr. 1993:24(3):325-329.

24. Weijer C, Miller PB. Protecting communities in pharmacogenetic and pharmacogenomic research. Pharmacogenomics J. 2004;4(1):9-16.

25. Manson S, ed. Am Indian Alsk Native Ment Health Res. [entire issue] 1989;2(3):5-90.

26. Davis SM, Reid R. Practicing participatory research in American Indian communities. Am J Clin Nutr. 1999;69(4)(Suppl):755S-759S.

27. Freeman WL, Romero FC, Kanade S. Community consultation to assess and minimize group harms. In: Amdur RJ, Bankert EA (eds). Institutional Review Board: Management and Function. 2nd ed. Sudbury, MA: Jones and Bartlett Publishers; 2006:Chapter 5-4,134-139.

28. Weijer C. Benefit-sharing and other protections for communities in genetic research. Clin Genet. 2000;58(5):367-368.

29. Weijer C, Goldsand G, Emanuel EJ. Protecting communities in research: current guidelines and limits of extrapolation. Nat Genet. 1999;23(3):275-280.

30. Hueston WJ, Mainous AG III, Weiss BD, Macaulay AC, Hickner J, Sherwood RA; North American Primary Care Research Group; Society of Teachers of Family Medicine. Protecting participants in family medicine research: a consensus statement on improving research integrity and participants' safety in educational research, community-based participatory research, and practice network research. Fam Med. 2006;38(2):116-120.

31. Quinn SC. Ethics in public health research: protecting human subjects: the role of community advisory boards. Am J Public Health. 2004;94(6):918-922.
32. National Health \& Medical Research Council. Values and Ethics: Guidelines for Ethical Conduct in Aboriginal and Torres Strait Islander Health Research. Canberra, ACT, Australia: National Health \& Medical Research Council, 2003. http://www.nhmrc.gov.au/_files_nhmrc/ file/health_ethics/human/conduct/guidelines/e52.pdf. Accessed Dec 24, 2009.

33. Canadian Institutes of Health Research. CIHR Guidelines for Health Research Involving Aboriginal People. Ottawa, ON, Canada: Canadian Institutes of Health Research, 2007. http://www.cihr-irsc.gc.ca/e/documents/ethics_aboriginal_guidelines_e.pdf. Accessed Dec 24, 2009.

34. Health Research Council of New Zealand. Guidelines for Researchers on Health Research Involving Ma-ori. Auckland, New Zealand: Health Research Council of New Zealand, 2008. http://www.hrc. govt.nz/assets/pdfs/publications/MHGuidelines\%202008\%20FINAL. pdf. Accessed Jan 4, 2010.

35. Quigley D. A review of improved ethical practices in environmental and public health research: case examples from native communities. Health Educ Behav. 2006;33(2):130-147.

36. Weijer C, Emanuel EJ. Ethics. Protecting communities in biomedical research. Science. 2000;289(5482):1142-1144.

37. Watkins BX, Shepard PM, Corbin-Mark CD. Completing the circle: a model for effective community review of environmental health research. Am J Public Health. 2009;99(Suppl 3):S567-S577.

38. Wallwork E. Ethical analysis of research partnerships with communities. Kennedy Inst Ethics J. 2008;18(1):57-85.

39. Macaulay AC, Commanda LE, Freeman WL, et al.; North American Primary Care Research Group. Participatory research maximises community and lay involvement. BMJ. 1999;319(7212):774-778.

40. Emanuel EJ, Wendler D, Grady C. An ethical framework for biomedical research. In: Emanuel EJ, Grady C, Crouch RA, et al (Eds). The Oxford Textbook of Clinical Research Ethics. New York, NY: Oxford University Press; 2008:123-135.

41. Brugge D, Missaghian M. Protecting the Navajo People through tribal regulation of research. Sci Eng Ethics. 2006;12(3):491-507.

42. Native American Law Center. Model Tribal Research Code. 3rd ed. Albuquerque, NM: Native American Law Center; 1999.

43. McGrath MM, Fullilove RE, Kaufman MR, Wallace R, Fullilove MT. The limits of collaboration: a qualitative study of community ethical review of environmental health research. Am J Public Health. 2009;99(8):1510-1514.

44. Williams RL, Shelley BM, Sussman AL; RIOS Net clinicians. The marriage of community-based participatory research and practice-based research networks: can it work? A Research Involving Outpatient Settings Network (RIOS Net) study. J Am Board Fam Med. 2009;22(4):428-435 